\title{
A presença da História da Matemática no desenvolvimento da Trigonometria do Triângulo Retângulo nos livros didáticos de Matemática do Ensino Médio
}

\author{
The presence of the History of Mathematics in the development of Right Triangle \\ Trigonometry in High School Mathematics textbooks
}

Wagner Marcelo Pommer
Universidade Federal de São Paulo (UNIFESP), Departamento de Ciências Exatas e da Terra
(DCET), Programa de Ensino de Ciências e Matemática (PECMA), Diadema, SP, Brasil
https://orcid.org/0000-0002-6138-1279, wagner.pommer@unifesp.br

Pedro Pereira de Almeida Júnior

Universidade Federal de São Paulo (UNIFESP), Diadema, SP, Brasil https://orcid.org/0000-0001-7744-0950, casteloforte326@bol.com.br

\section{Informações do Artigo \\ Como citar este artigo \\ POMMER, Wagner Marcelo; ALMEIDA JÚNIOR, Pedro Pereira de. A presença da História da Matemática no desenvolvimento da Trigonometria do Triângulo Retângulo nos livros didáticos de Matemática do Ensino Médio. REMAT: Revista Eletrônica da \\ Matemática, Bento Gonçalves, RS, v. 6, n. 1, p. 1-17, 14 maio 2020. DOI: \\ https://doi.org/10.35819/remat2020v6i1id3836}

\section{Histórico do Artigo}

Submissão: 15 de dezembro de 2019

Aceite: 9 de fevereiro de 2020.

\section{Palavras-chave}

Trigonometria

História da Matemática

Livro Didático

Ensino Médio

\section{Resumo}

D’Ambrosio (1996) aponta que a História da Matemática é uma área que pode trazer diversas contribuições ao ensino da Matemática. O objetivo desta pesquisa foi analisar se e como é abordada a História da Matemática em livros de Matemática do Ensino Médio em torno da "Trigonometria do Triângulo Retângulo". Como referencial teórico apoiamo-nos no fenômeno da vulgata (CHERVEL, 1990) e nos possíveis usos pedagógicos da História da Matemática. Como ferramenta de análise utilizamos a pesquisa documental descrita em Gil (2002) em uma amostra de três coleções de livros de Matemática do Ensino Médio, nos aspectos quantitativos e qualitativos. Como categorias de análise qualitativa adaptamos as considerações de Vianna (1995 apud BIANCHI, 2006) com relação aos usos da História da Matemática como motivação, informação, estratégia didática e desenvolvimento do conteúdo. Observamos que essas categorias foram encontradas nos livros didáticos e que trazem contribuições, mas devem ser complementadas por uma mediação adequada por parte do professor de Matemática.

\footnotetext{
Keywords

Trigonometry

History of Mathematics

Textbook

High School
}

\begin{abstract}
D'Ambrosio (1996) points out that the History of Mathematics is an area that can bring many contributions to the Mathematics teaching The aim of this research was to analyze if and how the History of Mathematics is presented in high school Mathematics textbooks related to the "Right Triangle Trigonometry". As theoretical reference we rely on the vulgata phenomena (CHERVEL, 1990) and on the possible pedagogical uses of the History of Mathematics. As a tool for analysis, we used the documentary research described in Gil (2002) in a sample of three High School Mathematics books collections, in quantitative and qualitative ways. As categories of qualitative analysis, we adapted Vianna's (1995 apud BIANCHI, 2006) considerations regarding the uses of the History of Mathematics as motivation, information, didactic strategy and subject development. We observed that these categories were found in the textbooks and that they bring contributions, but they must be complemented by an adequate mediation by the Mathematics teacher.
\end{abstract}




\section{Introdução}

Tashima e Silva (2015) apontam que o ensino de Matemática na escolaridade básica tem recebido contribuições de pesquisas na área da Educação Matemática. Algumas dessas estão inseridas em documentos oficiais como os Parâmetros Curriculares Nacionais, descritos em Brasil (1997; 1998) e na Base Nacional Comum Curricular, Brasil (2017).

Silva (2005), em sua pesquisa, conjecturou sobre a possibilidade que documentos oficiais possam ter ajudado a provocar modificações no ensino e na aprendizagem de Matemática. Nesse sentido, Silva (2005, p. 83) considera que

[...] tanto a publicação dos Parâmetros Curriculares Nacionais como o Programa Nacional do Livro Didático provocaram transformações na disciplina Matemática. É preciso, entretanto, aprofundar as análises nessas transformações de modo a compreender melhor como as ideias, sugestões, propostas contidas nesses documentos estão sendo apropriadas nas práticas pedagógicas.

Um importante indicador do processo de ensino são os livros didáticos, destacado por Nascimento, Silva e Pinheiro (2009, p. 1027), ao observarem que "[...] muitas vezes é a única fonte de consulta para o professor na preparação de suas aulas, determinando o conteúdo e até a metodologia na organização curricular".

Schubring (2005, p. 9), ao discutir a realidade sobre o ensino, faz a seguinte reflexão: "Com efeito, pesquisas da Educação Matemática têm mostrado que a realidade de dia-a-dia do ensino é determinada decisivamente pelos manuais (e não pelos programas curriculares)".

Os Parâmetros Curriculares Nacionais, descritos em Brasil (1997; 1998) e a Base Nacional Curricular Comum, conforme Brasil (2017), enfatizam a contextualização e a interdisciplinaridade. Consideramos que um dos recursos para promover esses dois quesitos se situa no uso da História da Matemática.

A inserção de elementos da História da Matemática $(\mathrm{HM})$ na escolaridade básica é uma das tendências emergentes da pesquisa em Educação Matemática, de acordo com D’Ambrosio (1996), Tzanakis e Arcavi (2000), Pais (2011), Panasuk e Horton (2013) e Carlini e Cavalari (2017).

Em particular, Panasuk e Horton (2013) apontam que a História da Matemática oferece

[...] uma perspectiva que estabelece as bases para o aprendizado. A História da Matemática pode ser vista como uma abertura para a teoria do assunto e provavelmente fornecerá uma oportunidade não ameaçadora para o aprendizado inicial de matemática. Em particular, pode ser benéfico para o aluno que tem dificuldades com a aprendizagem de matemática ${ }^{1}$ (p. 38, tradução nossa).

O tema "trigonometria" é um assunto presente no currículo oficial brasileiro, conforme situa a Base Nacional Curricular Comum, descrita em Brasil (2017). Os pesquisadores Silva (2005) e Ramalho e Bittar (2016) têm se debruçado para discutir, refletir e debater sobre como realizar o trabalho didático com a trigonometria no triângulo retângulo, a fim de encontrar propostas

1 " $[. .$.$] a perspective that lays a foundation for learning. The HOM may be viewed as a window into the theory$ of the subject and is likely to provide a non-threatening opportunity for entry learning of mathematics. In particular, it may be beneficial to the student whose learning of mathematics is a struggle". 
pedagógicas para favorecer a construção do conhecimento matemático por parte dos alunos da escolaridade básica.

Em face dos apontamentos realizados, o objetivo desta pesquisa foi analisar se e como é abordada a História da Matemática em livros de Matemática do Ensino Médio no entorno da "Trigonometria do Triângulo Retângulo".

\section{Referenciais Teóricos}

A vulgata pode delinear um conjunto de características e traços comuns compartilhados por certa comunidade em determinada época. Chervel define o fenômeno da vulgata (1990, p. 203) ponderando que em cada época

[...] o ensino dispensado pelos professores é, [a] grosso modo, idêntico, para a mesma disciplina e para o mesmo nível. Todos os manuais ou quase todos dizem então a mesma coisa, ou quase isso. Os conceitos ensinados, a terminologia adotada, a coleção de rubricas e capítulos, a organização do corpus de conhecimento, mesmo os exemplos utilizados ou os tipos de exercícios praticados são idênticos, com variações aproximadas.

Em particular, Silva (2005) considera que a análise de livros didáticos possibilita verificar como os autores apropriaram-se das legislações ou das recomendações em certo período. Nesse sentido, o fenômeno da vulgata pode ser revelado nos livros didáticos atuais aprovados no Programa Nacional do Livro Didático, pois ao se adequarem às exigências dos editais estes tendem a estigmatizar determinado espectro ou características essenciais compartilhadas em maior ou menor grau pelos membros de certa comunidade acadêmica.

Bianchi (2006, p. 87) aponta que a História da Matemática é um importante

[...] recurso didático para o ensino aprendizagem da Matemática e está sendo utilizada, cada vez com maior frequência. O Movimento da História da Matemática se intensificou e pode com isso trazer contribuições muito positivas [...]. Acreditamos que isso tem se refletido nos Livros Didáticos também, ratificando que os autores podem estar se 'alimentando' dos frutos desta institucionalização.

Esse processo de institucionalização observado por Bianchi (2006) é um sinal que a História da Matemática está cada vez mais presente nos livros didáticos e este é um aspecto importante de ser investigado, configurando indicativo de provável contribuição.

Um dos sustentáculos da presença da História da Matemática é mostrar que a Matemática não é fruto de um conhecimento pronto e acabado. Em face disso, o Guia de Livros Didáticos (PNLD 2018), descrito em Brasil (2018, p. 517), aponta que as práticas matemáticas "[...] variaram muito ao longo dos tempos, dependendo das necessidades, visões de mundo, entre outros fatores, e continuam a variar".

D’Ambrosio (1996) elege alguns motivos pelos quais se torna fundamental inserir a História da Matemática no ensino. Dentre estes destacamos que esta linha permite situar como teorias e práticas matemáticas foram criadas, desenvolvidas e utilizadas em determinado contexto específico de sua época, além de conhecer pontos relevantes da Matemática do passado. Para o 
autor, este movimento poderá, na melhor das hipóteses, orientar o processo do aprendizado ou ensino atual.

Costa (2003) revela que desde os primórdios do surgimento da trigonometria esta foi desenvolvida em diversos contextos da humanidade como resultado de necessidades práticas ligadas à astronomia, à agrimensura, ao comércio e à navegação. Esse saber construído historicamente remonta a um período tão grande que um dos primeiros indícios datam de 1650 a.C., por meio de achados importantes como o Papiro Ahmes no Egito, considerando que o surgimento da trigonometria envolveu também o povo babilônico.

Passamos, no próximo item, a apontar os referenciais metodológicos que nortearam a presente pesquisa com livros didáticos.

\section{Referenciais Metodológicos}

Nuñez et al. (2003) e Pimentel (2014) destacam que a análise de livros didáticos tem despertado interesse pela comunidade acadêmica. Para os referidos autores os estudos têm explorado os mais variados aspectos, como um objeto de análise em si mesmo, sobre o papel que os atores sociais desempenham na sua produção e utilização.

Pommer (2018) assinala que os livros didáticos têm influência considerável no processo de ensino, pois muitos professores o utilizam como fonte principal de conhecimento e de estruturação do trabalho didático na sala de aula. O autor aponta que, em geral, o livro didático segue os conteúdos indicados nas orientações curriculares oficiais, sendo raras as incursões para atualizar o conhecimento matemático difundido por este tipo de material.

A presente pesquisa é de natureza quantitativa e qualitativa, na modalidade exploratória. Sobre o modo exploratório Gil (2002, p. 41) diz que este "[...] têm como objetivo proporcionar maior familiaridade com o problema, com vistas a torná-lo mais explícito ou construir hipóteses".

Na modalidade exploratória Gil (2002) destaca que existem fontes primárias e secundárias. As fontes primárias remetem a uma relação direta com os fatos a serem analisados, sem filtragem anterior. Por outro lado, as fontes secundárias compreendem a pesquisa de dados ou informações que foram previamente tratadas por outros estudiosos e que são de domínio público.

Esta pesquisa situou os livros didáticos como fontes primárias. Elencamos como critérios adotados para a composição do corpus de pesquisa que as obras constassem do Guia do Programa Nacional do Livro Didático 2018 (BRASIL, 2018), assim como a escolha de editoras já estabelecidas há muitos anos no mercado editorial brasileiro e ainda com autores apresentando variada formação acadêmica, vivência profissional e tempo de experiência no mercado editorial.

Nesta pesquisa foi analisada a presença da História da Matemática em três livros didáticos do Ensino Médio, no tópico resolução de triângulos retângulos, conforme o Quadro 1. 
Quadro 1 - Coleções de livros didáticos de Matemática para o Ensino Médio escolhidos.

\begin{tabular}{|c|c|c|c|}
\hline Coleção (volumes 1, 2, e 3) & Autor(es) & Editora & Edição/Ano \\
\hline Matemática: Contexto e Aplicações & Luiz Roberto Dante & Ática & 3. ed./2016 \\
\hline Conexões com a Matemática & Fábio Martins de Leonardo & Moderna & 3. ed./2016 \\
\hline Matemática: Ciência e Aplicações & Gelson lezzi et al. & Saraiva & 9. ed./2016 \\
\hline
\end{tabular}

Fonte: Guia de Livros Didáticos do PNLD (BRASIL, 2018).

Para proceder a análise dos livros baseamo-nos em considerações de Vianna (1995) apud Bianchi (2006) e situamos as seguintes categorias: "História da Matemática como motivação", "História da Matemática como informação", "História da Matemática como estratégia didática" e "História da Matemática como parte integrante do desenvolvimento do conteúdo".

Vianna (1995) apud Bianchi (2006) levantou essas considerações envolvendo as quatro categorias a partir de seu estudo sobre o modo como a História da Matemática se situava nos Livros Didáticos na década de 1990.

No Quadro 2 apresentamos um modo de verificação das categorias delineadas, com a intenção de obter um perfil destas menções nos textos que permitam analisar a presença da História da Matemática envolvendo a resolução de triângulos retângulos.

Quadro 2 - Categorias de análise histórica para cada menção nas três coleções de livros didáticos.

\begin{tabular}{|c|c|}
\hline \multirow{2}{*}{ Categoria } & Características da cada categoria \\
\hline \multirow{2}{*}{ Motivação } & Aparece na forma de uma anedota no início do capítulo? \\
\cline { 2 - 2 } & Aparece na forma de uma lenda no início do capítulo? \\
\cline { 2 - 2 } Informação & É um breve texto introdutório do capítulo? \\
\cline { 2 - 2 } & $\begin{array}{c}\text { São dados adicionais que não complementam a resolução de problemas que } \\
\text { aparecem depois de concluído o conteúdo no capítulo? }\end{array}$ \\
\hline Estratégia Didática & Estimulam no aluno algum procedimento que tenha relação com o conteúdo? \\
\hline Uso Imbricado & A menção histórica é implícita (sem falar diretamente de nome de matemáticos ou \\
& sobre a História da Matemática)?
\end{tabular}

Fonte: Adaptado de Vianna (1995) apud Bianchi (2006).

Observamos que nossa opção em utilizar essa categorização baseou-se na oportunidade de utilizar um delineamento metodológico derivado de pesquisas que levaram em conta que Vianna se apoiou nas considerações relativas

[...] à prática do historiador, buscando compreender e enxergar de outra maneira o trabalho desse profissional, as relações entre história e ambiguidade, história e ciência, história e representações, o trabalho do historiador, história e representações e lógica histórica" (BIANCHI, 2006, p. 22). 


\section{Descrição e Análises}

Inicialmente, realizamos levantamento e análise quantitativa com relação às menções históricas identificadas nas coleções, de modo a verificar com que frequência as três coleções fizeram uso da História da Matemática em situações que envolveram a resolução de triângulos e trigonometria no triângulo retângulo em função dos conteúdos, que está ilustrado na Figura 1.

Figura 1 - Comparativo das menções históricas, por coleção, em função do conteúdo.

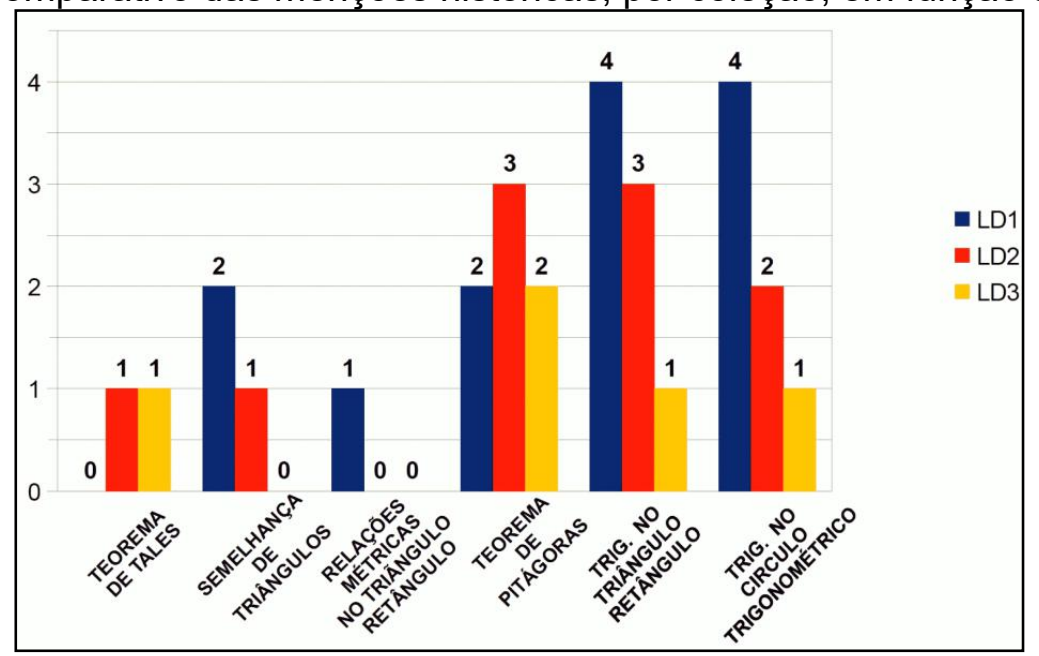

Fonte: Dados da pesquisa (2019).

A Figura 1 permitiu ter uma noção quantitativa mais específica por conteúdo sobre o número de inserções de menções históricas presentes em cada coleção. Em face do aspecto supracitado foi possível também a verificação de como as três coleções juntas, de maneira geral, trabalharam quantitativamente cada conteúdo, o que verifica as considerações de Bianchi (2006) com relação à possível presença da História da Matemática no material didático. Isso foi possível pelo levantamento do total de menções históricas por conteúdo matemático (Figura 2).

Figura 2 - Distribuição das menções por conteúdo matemático.

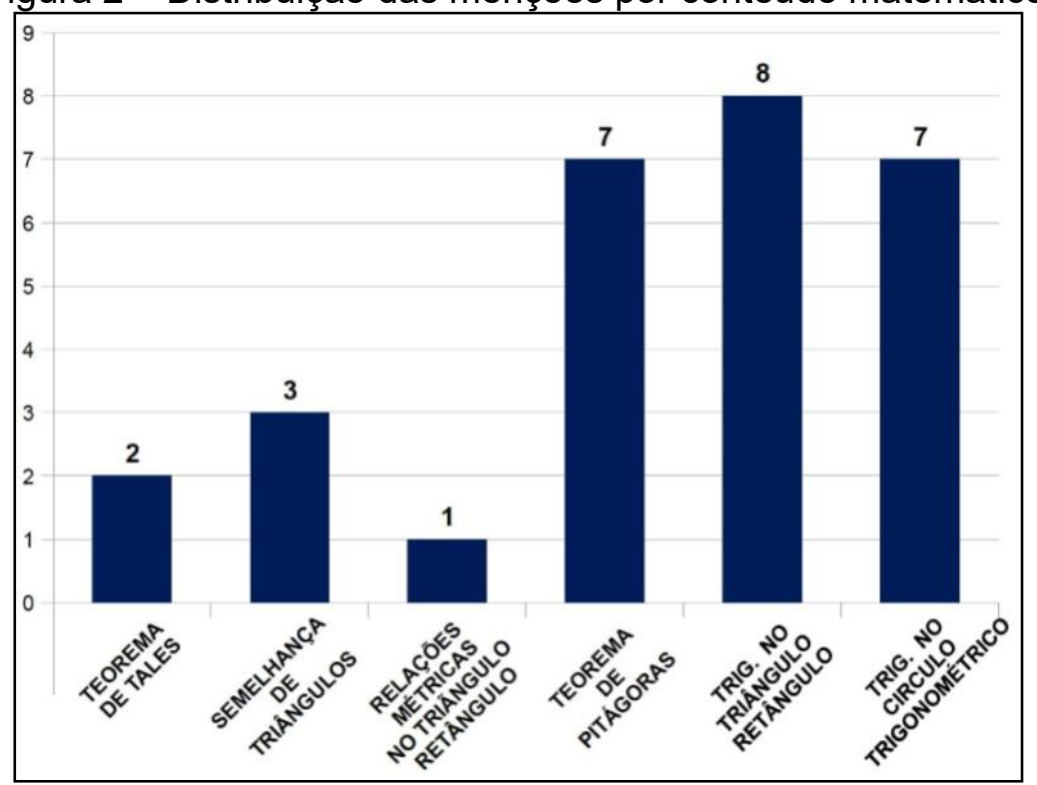

Fonte: Dados da pesquisa (2019). 
Pode-se constatar que as coleções enfatizaram três categorias na inserção da História da Matemática: o "Teorema de Pitágoras", a "Trigonometria no Triângulo Retângulo" e a "Trigonometria no Círculo Trigonométrico". Do ponto de vista mais particular, apresentamos os protocolos de alguns itens.

No volume 1 da coleção LD1 (DANTE, 2016), no início do tópico "Relações métricas no triângulo retângulo" há "menção histórica como motivação", conforme o Protocolo 1. O autor faz uma abordagem sobre a importância do triângulo retângulo na história remetendo-nos ao antigo Egito, onde se fazia uso de triângulos retângulos com nós espaçados de forma equidistante. Essa citação, associada à pesquisa em dupla proposta num pequeno quadro pontilhado, de alguma forma, pode ser considerada parcialmente como uma "menção histórica como estratégia didática".

Protocolo 1 - As relações métricas no triângulo retângulo pelos antigos egípcios no LD1.

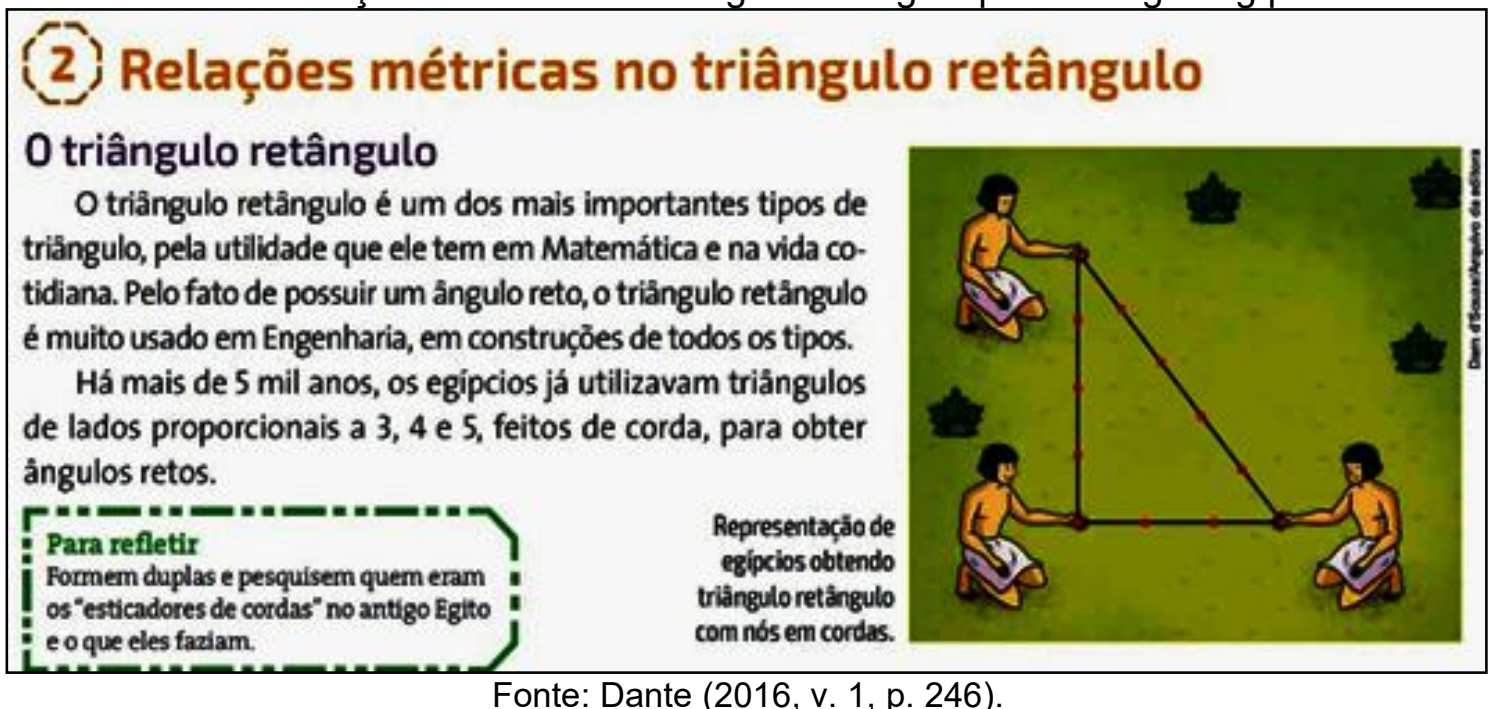

No Protocolo 2 há uma citação sobre outra abordagem que, segundo historiadores, seria atribuída aos gregos da antiguidade sobre uma demonstração geométrica do Teorema de Pitágoras. Esse tipo de abordagem deixa implícito a ideia de que o conhecimento matemático não é estático, mas passível de ser apreendido por meio da criatividade. Como essa citação encontrase em meio ao capítulo e carrega uma abordagem que explicita uma forma diferente e acessória para a compreensão do referido teorema, podemos considerar esta seção como uma "menção histórica como estratégia didática". 
Protocolo 2 - Demonstração do Teorema de Pitágoras no LD1.

O teorema de Pitágoras também pode ser demonstrado por comparação de áreas (segundo os historiadores, a demonstração de Pitágoras deve ter sido uma demonstração geométrica semelhante à que segue).

As duas regiōes quadradas a seguir têm lados de medidas $(b+c)$. Logo, têm a mesma área. Retirando das duas as quatro regiōes triangulares congruentes, o que sobra na primeira $\left(a^{2}\right)$ é igual ao que sobra na segunda $\left(b^{2}+c^{2}\right)$. Então: $a^{2}=b^{2}+c^{2}$.
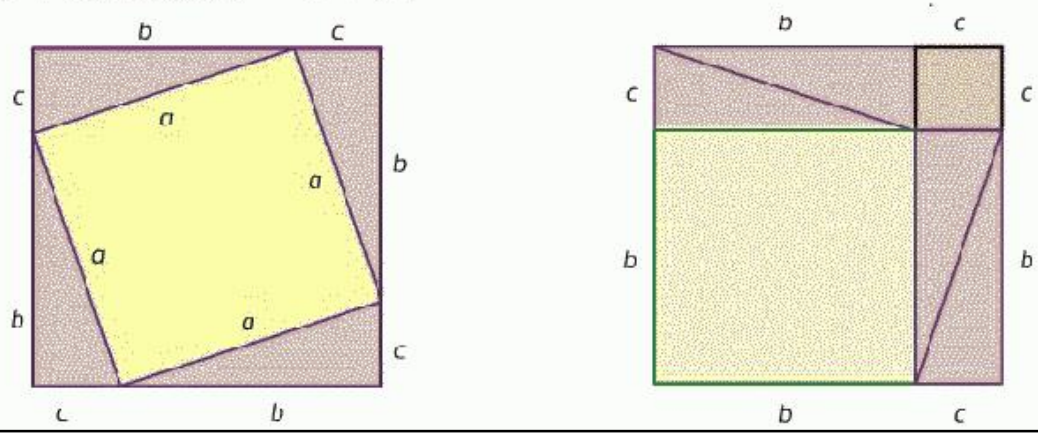

Fonte: Dante (2016, v. 1, p. 247).

O próximo protocolo menciona o cálculo dos senos e cossenos buscando um contexto moderno das calculadoras eletrônicas, conforme o Protocolo 3a.

Protocolo 3a - Apresentação dos senos e cossenos no LD1.

\section{A evolução do cálculo dos senos e cossenos}

Com uma calculadora cientifica você obtém facilmente senos e cossenos de qualquer ãngula. Por exem. plo, para saber o cosseno do ângulo de $20^{\circ}$ apertamos a tecla "cos" da calculadora, digitamos o número " 20 ", depois a tecla " $"$ " e aparece o número $0,93969 \ldots$.

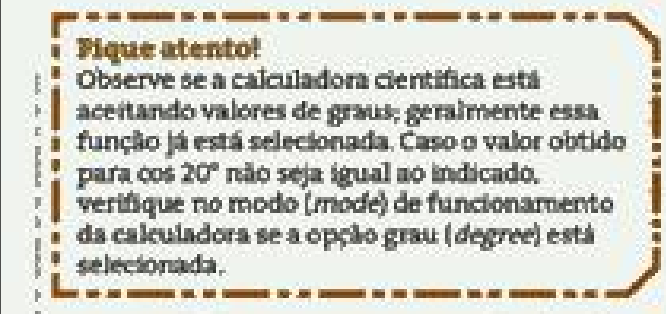

No século XVIII, com o Cálculo de Newton e Leibniz em pleno desenvolvimento, um matemático inglês chamado Brook Taylor descobriu que funçöes podem ser aproximadas por polinômios. Por exemplo, para calcular cos $x$ quando $x$ é um número real relativamente pequeno usamos o Polinómio de Taylor, que para a funçāo cosseno è:

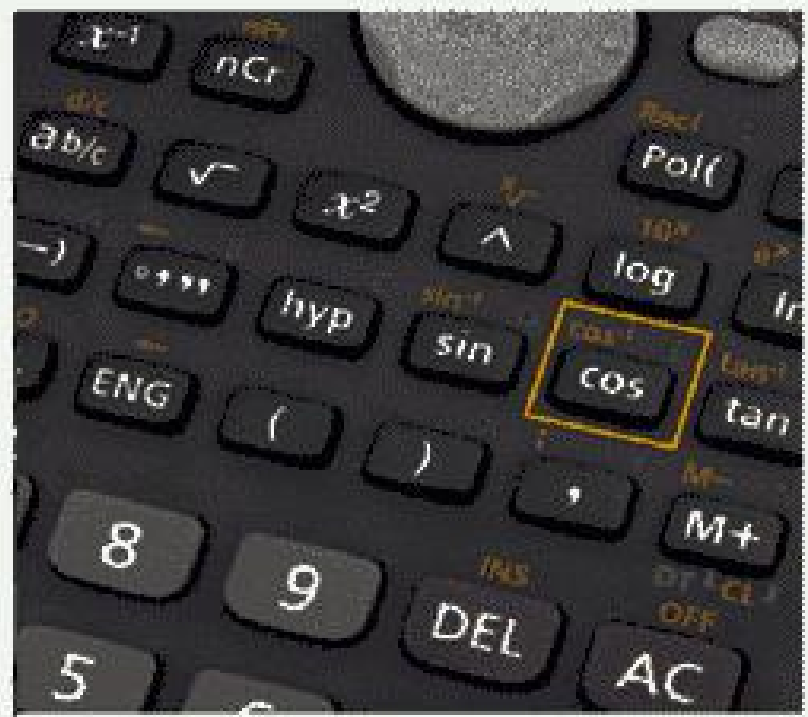

Detalhe de uma caterladora cientifica

Fonte: Dante (2016, v. 1, p. 256).

A seguir, no desenvolvimento do próprio texto, o livro mostra como os valores trigonométricos poderiam ser obtidos por uma série envolvendo polinômios e fatoriais de um número, o que perfaz um contexto mais atual do conhecimento matemático. 
Protocolo 3b - "A evolução do cálculo dos senos e cossenos" no LD1.

$$
\cos x=1-\frac{x^{2}}{2 !}+\frac{x^{4}}{4 !}-\frac{x^{6}}{6 !}+\frac{x^{3}}{8 !}-
$$

Quanto maior o número de parcelas, maior a precisảo obtida.

Na fórmula acima, aparece o simbolo de fatorial que quer dizer:

$$
n !=n(n-1)(n-2) \cdot \ldots \cdot 2 \cdot 1
$$

No nosso exemplo, para calcular (de forma aproximada) o cosseno de $20^{\circ}$, primeiro transformamos a medida do ângulo de graus para radianos:

$$
\left\{\begin{array}{l}
180^{\circ}=\pi \text { radianos } \\
20^{\circ}=x \text { radianos }
\end{array} \Rightarrow 180 x=20 \pi \Rightarrow x=\frac{20 \pi}{180} \Rightarrow x=\frac{5 \pi}{45} \Rightarrow x=\frac{\pi}{9}=0,3491\right.
$$

Tomando $20^{\circ}$ como 0,3491 radianos, substituimos esse valor de $x$ no Polinómio de Taylor, e, realizando os cálculos apenas até $-\frac{x^{6}}{6 !}$, encontramos o valor do cosseno de $20^{\circ}$, que é igual a 0,93968 , já com quatro casas decimais corretas.

A calculadora cientifica calcula as funçòes trigonométricas no momento em que vocẻ digita usando métodos desenvolvidos no século XVIII, mas com tecnologia moderna, que permite que cálculos pesados sejam feitos em um tempo infimo.

Fonte: Dante (2016, v. 1, p. 256).

A mescla entre áreas diversas da matemática está presente e pode provocar nos alunos um movimento de busca por um procedimento alternativo na resolução de certos problemas. Portanto, essa menção pode ser tratada como "menção histórica como informação" e parcialmente como "menção histórica como estratégia didática".

A seguir são apresentados alguns itens encontrados na coleção de livros didáticos LD2 (LEONARDO, 2016).

Protocolo 4 - "Tales e a semelhança" no LD2.

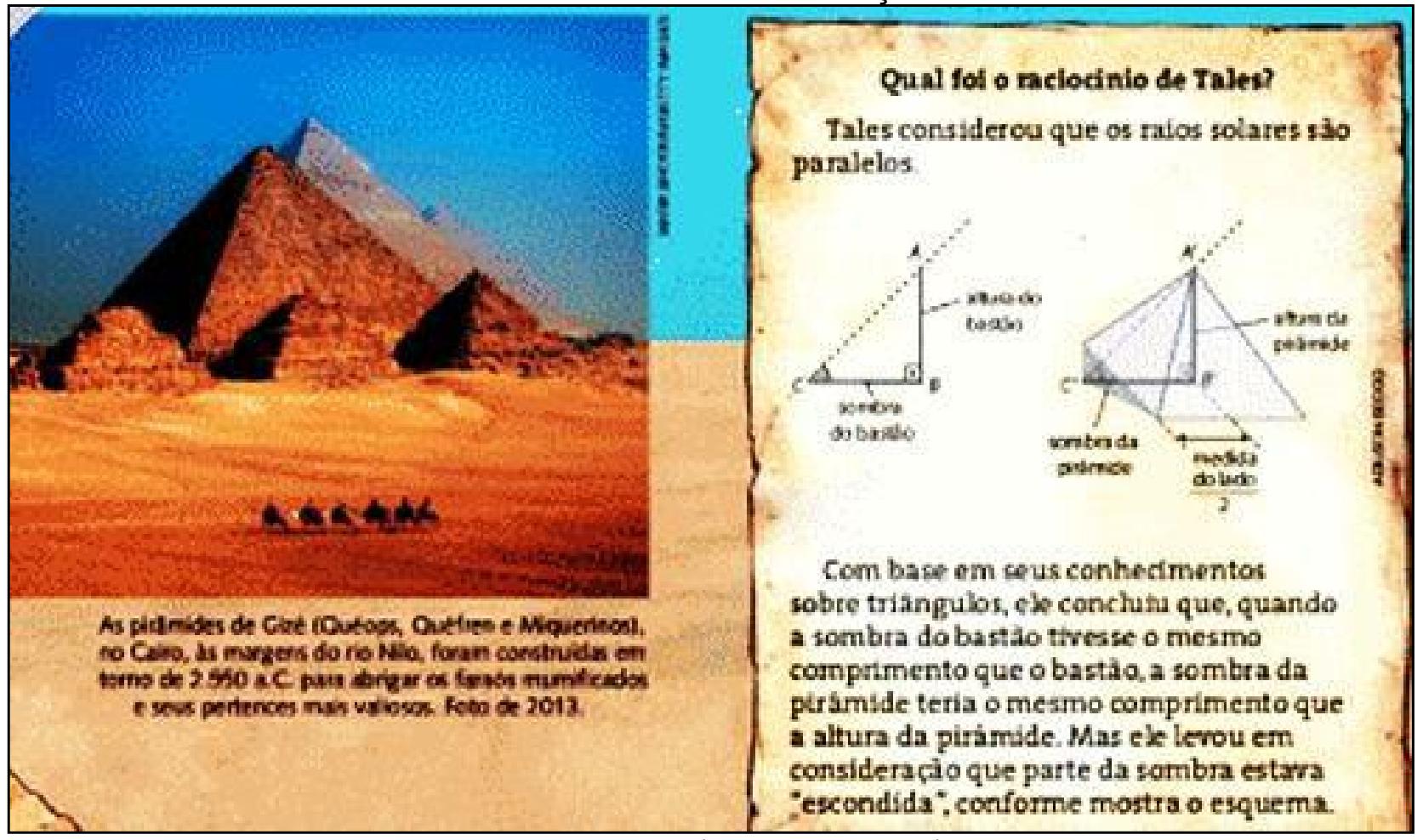

Fonte: Leonardo (2016, v. 1, p. 213). 
No início do Capítulo 10 do LD2 tem-se um exemplo de contextualização envolvendo a viagem de Tales ao Egito e o cálculo da altura de uma pirâmide baseado em conceitos de proporcionalidade. No Protocolo 4 há o esquema ilustrando a aplicação de semelhança de triângulos nas medidas conhecidas do bastão e a sombra da pirâmide, que permitiram a Tales o cálculo de sua altura. É importante notarmos que este texto introdutório é um exemplo que tende a subsidiar ao aluno certos conhecimentos úteis para a resolução de problemas onde são exigidas aplicações em situações semelhantes que envolvem cálculos de lados de triângulos com medidas proporcionais. Assim, esta seção pode ser colocada como "menção histórica como motivação" e também como "estratégia didática".

No Protocolo 5 há a apresentação de uma abordagem por meio de software.

Protocolo 5 - "Explorando o teorema de Pitágoras" no LD2.

\subsection{Explorando o teorema de Pitágoras}

Com o auxilio do computador, vamos explorar uma relaçăo que os gregos per ceberam há cerca de 2.500 anos.

Em um software de Geometria interativa, vamos acompanhat os seguintes passos:

\section{Construimos um triângulo retângulo qualquer.}

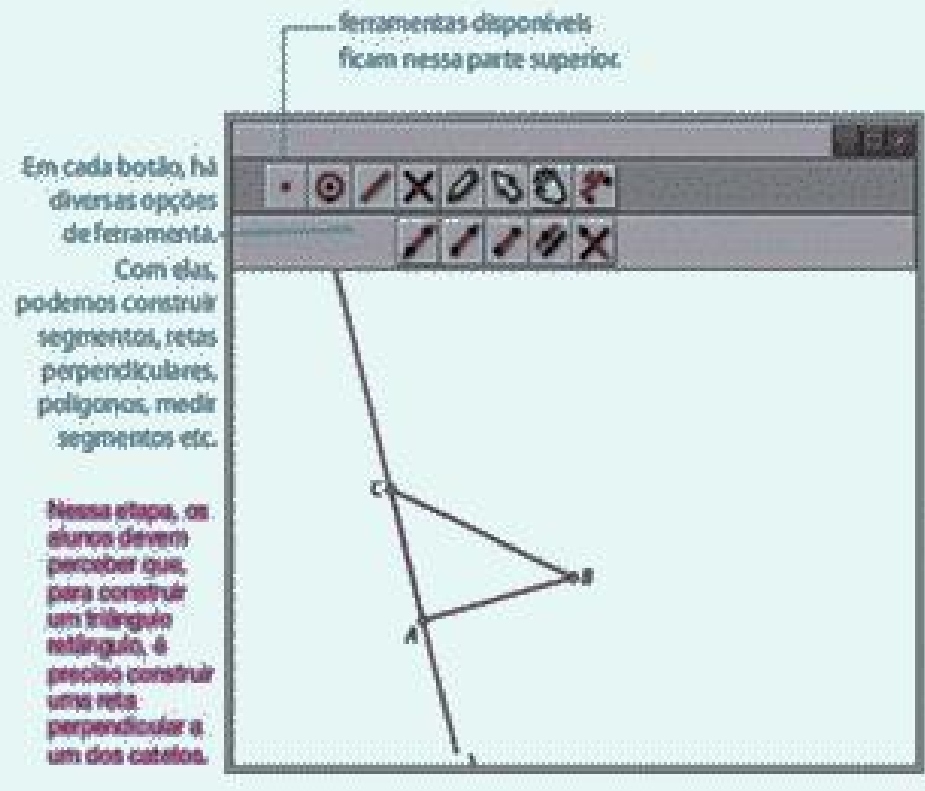

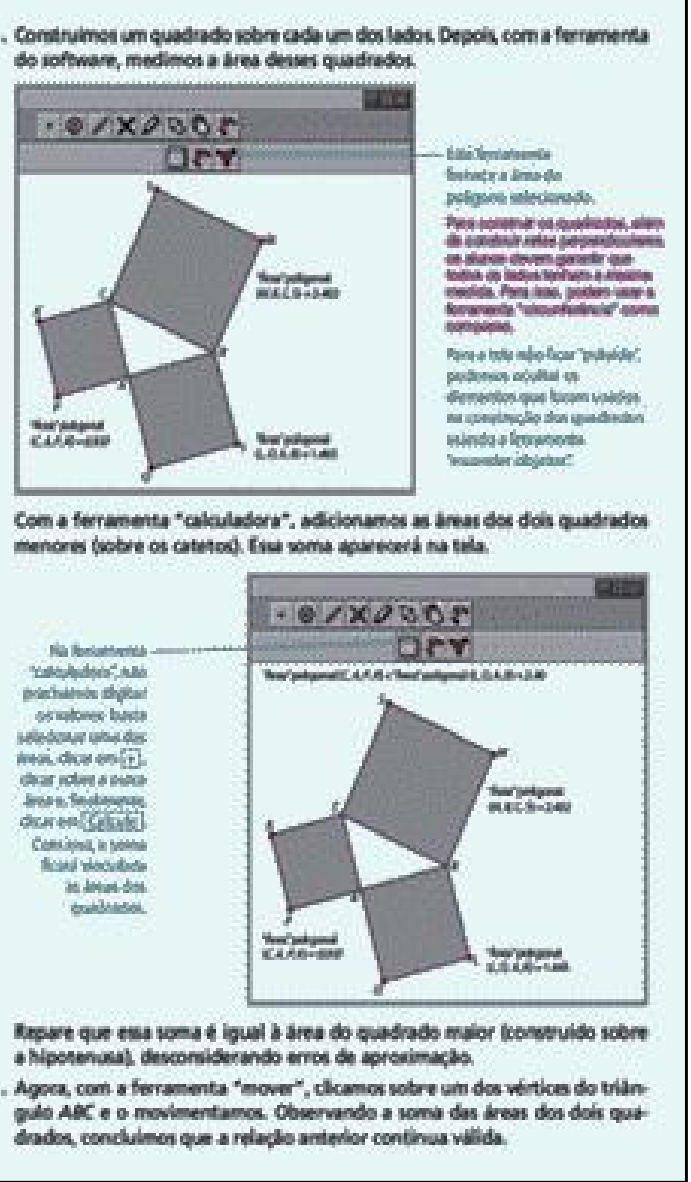

Fonte: Leonardo (2016, v. 1, p. 225).

Este modo de visualização do Teorema de Pitágoras é uma atualização e reedição da antiga concepção presente no livro de Euclides (cerca de 300 a.C.), por meio de uma apresentação envolvendo novas tecnologias. Essa menção histórica pode ser tratada como sendo de "estratégia didática".

A seguir, no Protocolo 6, o LD2 apresenta notas históricas sobre "Trigonometria notriângulo retângulo" onde se menciona como Aristarco de Samos empregou conhecimentos de trigonometria para fins astronômicos. 


\section{Protocolo 6 - "O cálculo de Aristarco de Samos" (LD2).}

Resolver problemas de Astronomia, como descobrir a distância entre a Terra, o Sol e a Lua, sempre despertou o interesse do ser humano. Desse tipo de especulação nasceu a Trigonometria, parte da Matemática que se dedica ao estudo das relaçōes entre as medidas dos lados e dos ângulos de um triângulo.

O grego Aristarco de Samos (310 a.C.-230 a.C.), considerado por muitos o primeiro grande astrônomo da História, usou as ideias da Trigonometria ao estabelecer um método geométrico para investigar a razão entre as distâncias Terra-Sol e Terra-Lua.

Seus cálculos partiram da observação de que, quando a Lua está no quarto crescente - ocasião em que exatamente metade dela aparece iluminada pelo Sol -, o ângulo $\hat{L}$, do triângulo formado entre o Sol $(S)$, a Terra $(T)$ e a Lua $(L)$, mede $90^{\circ}$, conforme esquema abaixo.

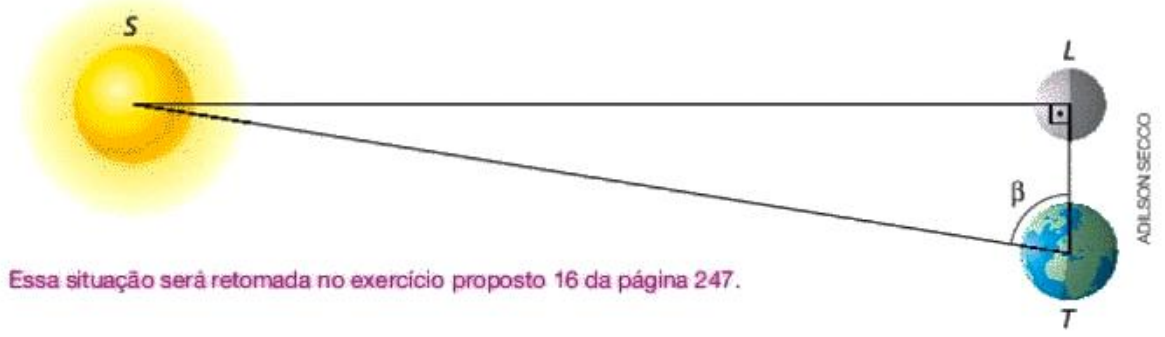

Aplicando os conhecimentos da época, Aristarco observou que o ângulo $\beta$, formado entre as linhas de vista da Terra ao Sol e da Terra à Lua, media $87^{\circ}$. A partir disso, com base em conceitos trigonométricos, concluiu que a razão entre as distâncias Terra-Sol e Terra-Lua $\left(\frac{T S}{T L}\right)$ estaria entre 18 e 20 , o que significa que a distância Terra-Sol era 18 a 20 vezes a distância Terra-Lua.

Hoje, sabemos que a distância Terra-Solé cerca de 400 vezes a distância Terra-Lua. A grande diferença entre esse valor e o encontrado por Aristarco está relacionada ao ângulo $\beta$, cuja medida correta é de aproximadamente $89,83^{\circ}$. Mesmo assim, o raciocínio de Aristarco foi perfeito.

Neste capitulo, estudaremos conceitos básicos da Trigonometria no triângulo retângulo e veremos que ela tem grande aplicação no cálculo de distâncias inacessiveis: na Astronomia, como fez Aristarco; na Topografia, para determinar a altura de morros, montanhas e colinas; na Engenharia, para estabelecer o comprimento de uma rampa etc.

$$
\text { Fonte: Leonardo (2016, v. 1, p. 237). }
$$

Essa citação pode ser tratada como uma contextualização e utilização "histórica como motivação". Ainda, a referida situação pode servir de estopim para que o professor explore o conteúdo, o que pode fomentar o uso como "estratégia didática".

Ao final do mesmo capítulo, no mesmo livro didático, há um exercício proposto para o cálculo da distância entre o Sol e a Terra e a razão entre a referida distância e da Terra e a Lua. Pode-se dizer que esta é uma "menção histórica como estratégia didática", conforme destacado no Protocolo 7. 


\section{Protocolo 7 - Exercício sobre a "ideia de Aristarco" (LD2).}

16. Vamos voltar à ideia de Aristarco, vista na página 237. Quando a Lua está no quarto crescente, um triângulo retângulo LTS é formado entre a Lua, a Terra e o Sol, conforme mostra a figura.

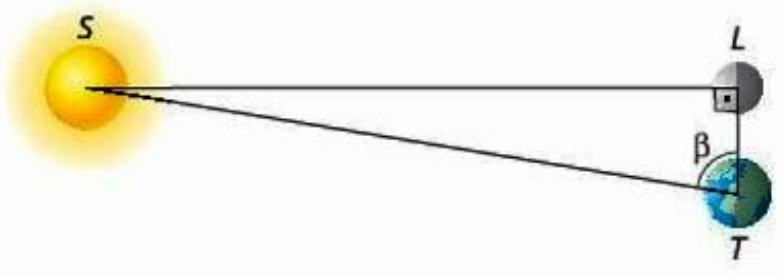

Sabendo que o ângulo $\beta$ mede aproximadamente $89,83^{\circ}$ e considerando que $T L=380.000 \mathrm{~km}$, determine:
a) a medida $T S$.
$\approx 131.034 .482 \mathrm{~km}$
b) a razão $\frac{T S}{T L},=345$

Fonte: Leonardo (2016, v. 1, p. 247).

Passamos agora a expor as menções históricas presentes na coleção LD3 (IEZZI et al., 2016). Na seção intitulada "Um pouco de História" é mostrado um resumo sobre o personagem Pitágoras de Samos, conforme indicado no Protocolo 8.

Protocolo 8 - "Notas históricas sobre Pitágoras" (LD3).

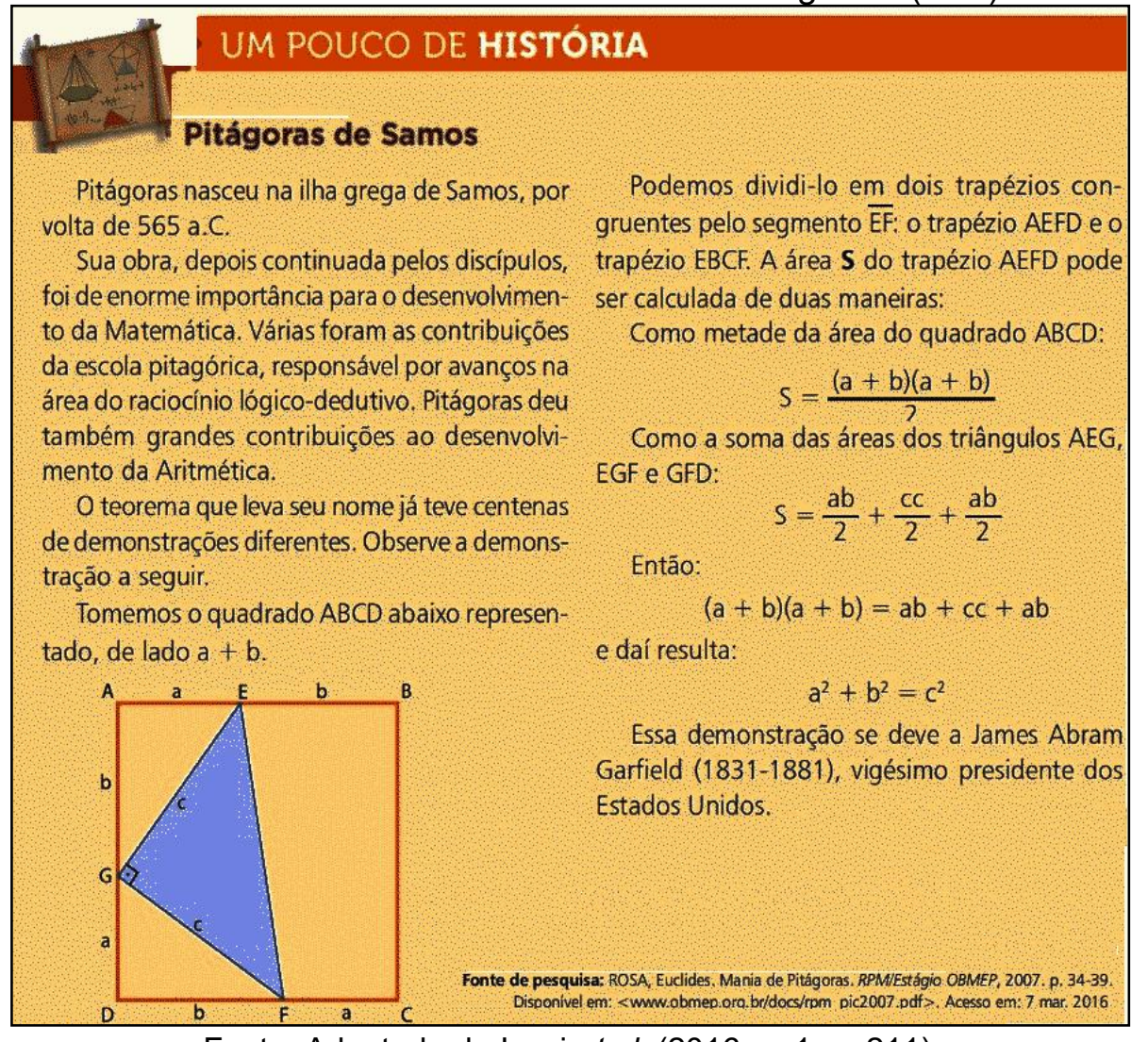

Fonte: Adaptado de lezzi et al. (2016, v. 1, p. 211).

Essa citação encontra-se em meio ao capítulo "Semelhança e triângulos retângulos", onde se destaca uma demonstração do Teorema de Pitágoras por meio de uma abordagem geométrica, dividindo um quadrado em dois trapézios congruentes. A menção pode ser tratada como "história 
como informação" e como "estratégia didática" por conter uma demonstração Matemática diretamente atrelada ao desenvolvimento de conceitos matemáticos presentes no ensino atual.

Ainda no LD3, há uma seção intitulada "Um pouco de História" (nas páginas 214 e 215), onde é mostrado um texto sobre as origens da Trigonometria, que se caracteriza como "menção histórica como motivação".

No volume 2 da coleção LD3, ao final do capítulo intitulado "A circunferência trigonométrica" encontramos a seção "Aplicações", onde o autor elabora um longo texto baseado em notas históricas, de forma a realizar uma prática interdisciplinar entre a Matemática e a Astronomia. No Protocolo 9 é apresentado um recorte deste texto, onde Eratóstenes aplica conhecimentos de trigonometria para determinar a distância entre Siena e Alexandria e também o comprimento da circunferência da Terra.

Protocolo 9 - "Medindo distâncias inacessíveis" no LD3.

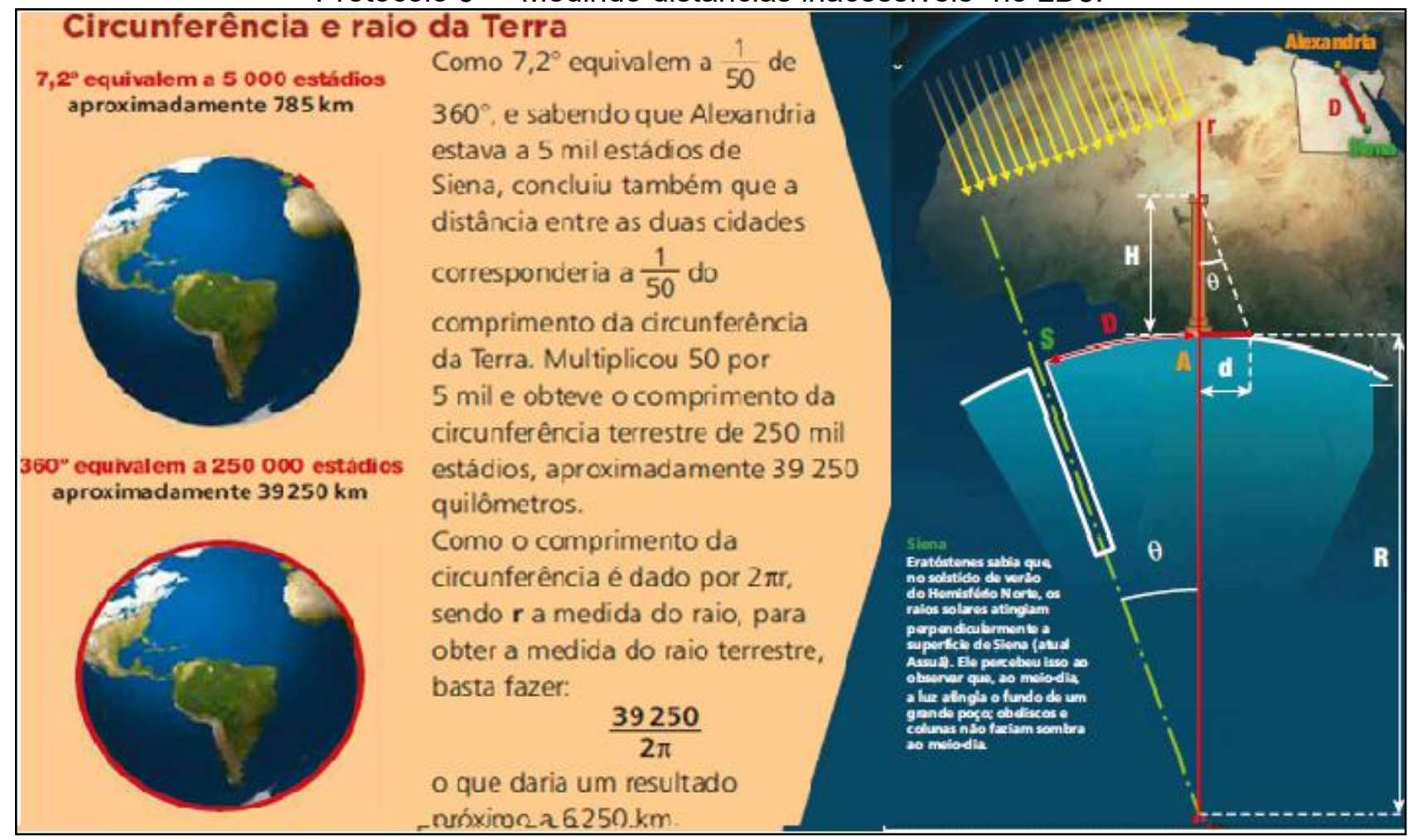

Fonte: Adaptado de lezzi et al. (2016, v. 2, p. 18-19).

Vale ressaltar que o autor pontua o raciocínio elaborado por Eratóstenes, inclusive em uma época onde poucos consideravam a Terra como corpo redondo. No primeiro caso, Eratóstenes calculou a distância entre as duas cidades com base no tempo de viagem das caravanas obtendo um resultado de 5 mil estádios, o que corresponde a aproximadamente 785 quilômetros.

Ainda, o grego calculou, durante um solstício que ocorreu em Alexandria e em Siena, por meio de um instrumento, que se acredita ser algo como uma vareta ou uma coluna fincada ao chão, o ângulo entre a vareta e os raios solares por meio da sombra formada, obtendo $7,2^{\circ}$. Assim, aplicando o conceito geométrico de "retas paralelas cortadas por uma transversal", Eratóstenes calculou o comprimento da circunferência da Terra, obtendo um resultado próximo a $6250 \mathrm{~km}$. 
Essa menção pode ser tratada como "histórica como informação" e também como "estratégia didática", visto que possui uma explicação matemática que poderia ter sido mais detalhada nos registros próprios da matemática.

\section{Considerações Finais}

Considerando-se os dados e as análises realizadas de alguns momentos de utilização da História da Matemática passamos a apresentar a síntese. Muitas das menções históricas compartilharam uma dupla categoria de funções. Na Figura 3 temos o número de menções em função tipo de categorias que as coleções fizeram uso de forma conjunta.

Figura 3 - Total de menções históricas em função da categoria presente nas três coleções.

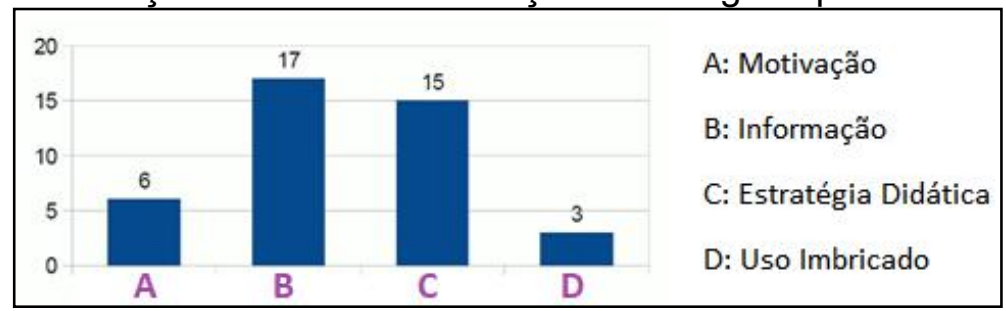

Fonte: Dados da pesquisa (2019).

Na Figura 4 apresentamos um comparativo entre as três coleções sobre as categorias de menções históricas exploradas por cada coleção, referentes à presença da História da Matemática envolvendo a resolução de triângulos e a Trigonometria.

Figura 4 - Número de menções históricas em função da categoria por coleção.

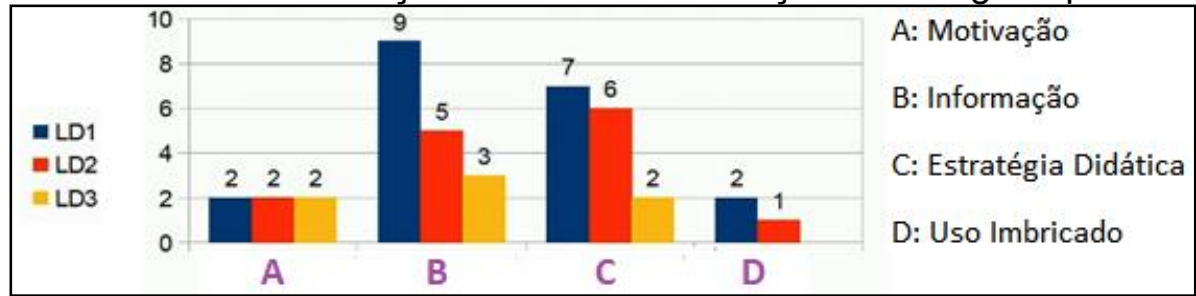

Fonte: Dados da pesquisa (2019).

É importante salientar que nas três coleções de livros didáticos estão presentes situações envolvendo a História da Matemática de forma contextualizada. Porém, observamos que este recurso de apresenta com diversos graus de intensidade, que são aqueles categorizados na Figura 4, fator que está de acordo com as premissas dos Parâmetros Curriculares Nacionais (BRASIL, 1998) e da Base Nacional Curricular Comum (BRASIL, 2017).

Destacamos alguns protocolos anteriormente apresentados, nomeadamente "As relações métricas no triângulo retângulo pelos antigos egípcios" (Protocolo 1), "Tales e a semelhança" no LD2, "os cálculos efetuados por Aristarco sobre as distâncias relativas entre o Sol, a Terra e a Lua" (Protocolo 4) e "O cálculo de Aristarco de Samos" (Protocolo 6). 
Nesses dados constatamos explícita intenção em se fazer uso da História da Matemática para se iniciar um trabalho didático para o ensino de Geometria, de modo a fomentar a interdisciplinaridade, algo extremamente desejado nas atuais pesquisas de historiografia.

O fato de aparecerem nos livros menções sobre as contribuições para a Trigonometria por meio de diferentes civilizações (egípcia, babilônica e grega) e povos (indiano, iraniano, dentre outros) em diferentes épocas até os séculos mais recentes destacam que esses conhecimentos não apareceram prontos e acabados. Acreditamos que é nestes momentos que pode se constatar o valor das menções históricas como "motivação" e "informação", conforme apontado em Vianna (1995, apud BIANCHI, 2006), visto que nestas também se encontram narrativas que podem contribuir para aguçar a percepção do conhecimento matemático como uma construção gradual de alguns indivíduos ou grupos de indivíduos e passíveis de aperfeiçoamento com o decorrer do tempo.

A constatação da presença da História da Matemática nas quatro categorias que observamos coaduna com as demandas dos documentos curriculares atuais e com algumas das preocupações de pesquisas atuais. Isso configura um movimento inicial para um processo de composição de uma nova vulgata (CHERVEL, 1990).

Porém, as poucas propostas de História da Matemática necessitam de maior engajamento com o desenvolvimento dos temas no livro didático. Assim, pelo que observamos, apesar deste passo inicial, ainda cabe ao protagonismo do professor enquanto mediador no processo de ensino e aprendizagem a tarefa de incrementar o potencial didático da História da Matemática em sala de aula. Esse mote pode se configurar um ensejo para que os autores de livros didáticos se atualizem nas pesquisas em historiografia e didática, pois o livro didático deve materializar propostas que estejam em consonância com a condução de práticas em que o professor possa mobilizar os alunos em movimento de aprendizagem.

\section{Referências}

BIANCHI, M. I. Z. Uma reflexão sobre a presença da História da Matemática nos livros

didáticos. 2006. 103 f. Dissertação (Mestrado em Educação Matemática) - Instituto de Geociências e Exatas, Universidade Estadual de São Paulo, Rio Claro, 2006.

BRASIL. Base Nacional Comum Curricular: Ensino Médio. Brasília: Ministério da Educação, 2017.

BRASIL. Guia de Livros Didáticos PNLD 2018: Matemática - Ensino Médio. Brasília: Ministério da Educação, 2018.

BRASIL. Parâmetros Curriculares Nacionais: Ensino Fundamental - Matemática. Brasília: Ministério da Educação, 1997.

BRASIL. Parâmetros Curriculares Nacionais: Ensino Médio. Brasília: Ministério da Educação, 1998. 
CARLINI, E. M. P.; CAVALARI, M. F. As funções didáticas da História da Matemática nos livros didáticos de Matemática do Ensino Médio. Hipatia, São Paulo, v. 2, n. 2, p. 73-88, dez. 2017.

CHERVEL, A. História das disciplinas escolares: reflexões sobre um campo de pesquisa. Teoria e Educação, Porto Alegre, v. 2, n. 2, p. 203, 1990.

COSTA, N. M. L. A História da Trigonometria. Educação Matemática em Revista, Chapecó, n. 10, p. 60-69, 2003.

D’AMBROSIO, U. História da Matemática e Educação. In: Cadernos CEDES, 40 - História e Educação Matemática. Campinas: Papirus, 1996, p.7-17.

DANTE, L. R. Matemática: Contextos e Aplicações. 3. ed. São Paulo: Ática, 2016.

GIL, A. C. Como elaborar projetos de pesquisa. 4 ed. São Paulo: Atlas, 2002.

IEZZI, G.; DOLCE, O.; DEGENSZAJN, D.; PÉRIGO, R.; ALMEIDA, N. de. Matemática: Ciência e Aplicações. 9. ed. São Paulo: Saraiva, 2016.

LEONARDO, F. M. Conexões com a Matemática. 3. ed. São Paulo: Moderna, 2016.

NASCIMENTO, M.; SILVA, S. C. R.; PINHEIRO, N. A. M. O ensino de geometria e os livros didáticos do Ensino Médio: uma análise. In: SIMPÓSIO NACIONAL DE ENSINO DE CIÊNCIAS E TECNOLOGIA, 1., 2009, Ponta Grossa. Anais... Ponta Grossa: UTFPR, p. 1027-1035, 2009.

NÚÑEZ, Isauro Beltrán; RAMALHO, Betânia Leite; SILVA, Ilka Karine P. da; CAMPOS, Ana Paula N. A seleção dos livros didáticos: um saber necesario ao professor. O caso do ensino de Ciências. Revista Iberoamericana de Educación, v. 1681, p. 56-63, 2003.

PAIS, L. C. Didática da Matemática: uma análise da influência francesa. 3. ed. Belo Horizonte: Autêntica, 2011.

PANASUK, R. M.; HORTON, L. B. Integrating History of Mathematics into the Classroom: Was Aristotle Wrong? Journal of Curriculum andTeaching. v. 2, n. 2, p.37-46, 2013.

PIMENTEL, G. H. A História da Geometria nos livros didáticos e perspectivas do PNLD. 2014. 138f. Dissertação (Mestrado em Educação) - Universidade Federal de São Carlos, São Carlos, 2014.

POMMER, M. W. Números irracionais na escolaridade básica: as contribuições didáticoepistemológicas advindas da História da Matemática. Revista de Ensino de Ciências e Matemática, São Paulo, v. 9, n. 3, p. 183-199, 2018.

SCHUBRING, Gert. Pesquisar sobre a história do ensino da Matemática: metodologia, abordagens e perspectivas. In: MOREIRA, Darlinda; MATOS, José Manuel (Orgs.). História do Ensino da Matemática em Portugal: Actas do XIII Encontro de Investigação em Educação Matemática. Beja: Sociedade Portuguesa de Ciências da Educação, 2005. Disponível em: http://spiem.pt/DOCS/ATAS ENCONTROS/atas EIEM 2004.pdf. Acesso em: 8 maio 2020.

SILVA, M. C. L. A. Geometria escolar ontem e hoje: algumas reflexões sobre livros didáticos de Matemática. Union, n. 3, p. 73-85, set. 2005. 
RAMALHO, L. V.; BITTAR, M. Uma análise da proposta de ensino da trigonometria em livros didáticos do $9^{\circ}$ ano do Ensino Fundamental. In: SEMINÁRIO SUL-MATO-GROSSENSE DE PESQUISA EM EDUCAÇÃO MATEMÁTICA, 10., 2016, Campo Grande. Anais... Campo Grande: UFMS, p.114-127, 2016.

TASHIMA, M. M.; SILVA, A. L. As lacunas no ensino-aprendizagem da Geometria. Londrina, 2015.

TZANAKIS, C.; ARCAVI, A. Integrating History of Mathematics in the classroom: an analytic survey. In: FAUVEL, J.; MAANEN, J. (Eds.). History in Mathematics Education. The ICMI Study.

Dordrecht: Kluwer Academic Publishers, p. 201-240, 2000. 